\title{
La concepción jurídico-constitucional de la cooperativa en Cuba \\ Un reto para el perfeccionamiento del modelo socioeconómico nacional
}

\author{
Orestes Rodríguez Musa* \\ Universidad de Pinar del Río \\ (Cuba)
}

Sumario: Introducción. I. La cooperativa y su identidad. II. La cooperativa como figura jurídica. III. La concepción juríudica de la cooperativa en el constitucionalismo cubano. Retos actuales. Conclusiones.

Resumen: El objetivo de este trabajo es aportar algunas valoraciones en torno a la concepción de la cooperativa en el constitucionalismo cubano, destinadas a que el magno texto pueda guiar - como corresponde - la implementación legal de la figura hacia una perspectiva integral. Para conseguir este propósito, ofreceremos inicialmente una caracterización de la institución que nos ilustre sobre su identidad. A continuación se analizará la dimensión jurídica de la cooperativa, ponderando las diferentes posturas doctrinales que han intentado definir su naturaleza. Por último, argumentaremos que la actual preceptiva constitucional cubana, influida por una reducida concepción de la institución, adolece de un grupo de limitaciones que obstaculizan el óptimo aprovechamiento de la figura en un contexto socioeconómico en el que está llamada a trascender.

Palabras clave: cooperativa, naturaleza jurídica, Constitución cubana.

Abstract: The objective of this work is to contribute with some valuations around the conception of the cooperative in the Cuban constitutionalism, dedicated to that the constitution can guide - like it corresponds - the legal im-

* Profesor de Derecho Constitucional en el Departamento de Derecho de la Facultad de Ciencias Sociales y Humanísticas de la Universidad de Pinar del Río, Cuba. Licenciado en Derecho por la Facultad de Derecho de la Universidad de la Habana (2006) y Máster en Derecho Constitucional y Administrativo por la propia institución (2010). Investigador del Centro de Estudios de Desarrollo Cooperativo y Comunitario (CEDECOM) adscrito a la Universidad de Pinar del Río, Cuba e investigador de la Asociación Internacional de Derecho Cooperativo (AIDC) con sede en la Universidad de Deusto, España. E-mail: musa@fcsh.upr.edu.cu 
plementation of the figure toward an integral perspective. To get this purpose, we will offer a characterization of the institution that illustrates us about their identity. Next it will be analyzed the juridical dimension of the cooperative, pondering the different doctrinal postures that have tried to define its nature. Lastly, we will argue that the current norms of the Cuban constitutional design, influenced by a reduced conception of the institution, suffers of a group of limitations that block the good use of the figure in a socioeconomic context in which it is called to transcend.

Key words: cooperative, juridical nature, Cuban Constitution. 


\section{Introducción}

Desde todas las latitudes y desde los más disímiles enfoques de la ciencia, se han dedicado grandes esfuerzos al estudio de la cooperativa, de donde han devenido fuertes polémicas sobre su identidad. La óptica jurídica de la materia no ha sido una excepción en este debate, pues si bien corresponde al Derecho canalizar la evolución de la cooperativa hacia apropiados derroteros, no siempre han comprendido sus hacedores y operadores en general, que la figura exige de nuevos patrones teóricos y técnicos. A consecuencia de ello, en múltiples ocasiones se ha encuadrado a la cooperativa dentro de instituciones jurídicas de otra naturaleza1', limitándose así sus potencialidades.

La vigente regulación constitucional de la cooperativa en Cuba, determinada por patrones ideológico-políticos desfavorables para el desarrollo integral de la figura, resulta un claro ejemplo de lo anterior. Sin embargo, el país se adentra hoy en un proceso de perfeccionamiento de su modelo socioeconómico en el que esta forma de gestión está llamada a ocupar un papel trascendental. Por tanto, el objetivo de este trabajo es aportar algunas valoraciones en torno a la concepción de la cooperativa en el constitucionalismo cubano, a fin de contribuir al oportuno perfeccionamiento de su regulación jurídica.

\section{La cooperativa y su identidad}

No es objetivo de este trabajo arribar a una conceptualización de la cooperativa, que con seguridad sería susceptible — por incompletade fundadas críticas; preferimos optar —siguiendo a KAPLAN DE DRIMER y DRIMER ${ }^{2}$ - por una caracterización básica de la figura que, sin cubrir a cabalidad todas y cada una de sus cualidades, al menos nos ilustre sobre su merecida y ventajosa identidad, a lo cual agregaremos algunas valoraciones en torno a sus actuales líneas de tendencia.

1 Vid. (entre otros) Kaplan de Drimer, A., «Las cooperativas ante los peligros de "Desnaturalización" y "Desmutualización"», en Anuario de Estudios cooperativos, Universidad de Deusto, España, año 2000, pp. 167 a 175; Unai del Burgo, D.: «La desnaturalización de las cooperativas. Estudio de los instrumentos financieros de carácter societario y del modelo de expansión "no-cooperativo" de Eroski S. Coop.», en Boletín de la AIDC, año 2002, pp. 51 y ss., consultado en www.aidc.deusto.es, diciembre de 2010.

2 Vid. Kaplan de Drimer, A. y Drimer, B., Las cooperativas. Fundamentos-HistoriaDoctrina, Ed. Intercoop, Buenos Aires, 1981, pp. 23-27. 
a) Entidades integradas por grupos de personas con el objetivo de atender a sus propias necesidades socioeconómicas, sobre la base del esfuerzo propio y la ayuda mutua.

Las cooperativas proporcionan servicios para satisfacer una o varias de las necesidades socioeconómicas experimentadas por núcleos más o menos numerosos de personas. Dichas necesidades no pueden ser satisfechas -o lo son de forma insuficiente- cuando estos individuos operan de manera aislada. Sin embargo, una vez que aúnan y complementan sus esfuerzos todas estas personas que se hallan en condiciones semejantes, logran conseguir una solución satisfactoria a sus problemas.

En este sentido requiere especial análisis la mutualidad, aspecto que ha generado fuertes disputas, pues para algunos significa un rasgo consustancial a la cooperativa y para otros no. No obstante, en la actualidad, la polémica parece disiparse.

Con la mutualidad se alude a la doble condición de socio-usuario de los miembros de la cooperativa, o sea que "...la actividad empresarial, cuyo desarrollo constituye el objeto social de la cooperativa, tenga como (...) destinatarios a los socios de la misma que, de este modo, satisfacen la necesidad que les llevó a participar en la constitución de la sociedad cooperativa» ${ }^{3}$. Y es que sus miembros participan no solo aportando las sumas de capital necesarias para su funcionamiento, sino además como proveedores en las cooperativas de producción, como clientes en las de consumo y como trabajadores en las de trabajo asociado.

Pese a que bajo el rubro de mutualidades se reconocen a otras figuras (instituciones caritativas, obras de beneficencias, etc.), lo que diferencia al fenómeno cooperativo de otras actividades genéricamente mutualistas, es justamente el constituirse para el desarrollo de una empresa; quizás sea esto causa fundamental para que su concepción doctrinal y legal esté sufriendo importantes trasformaciones.

En opinión de CANO LÓPEZ, «la cooperativa solo será socialmente útil si es capaz de operar en el mercado sometida a criterios de economicidad, (...) y ello exige un real y progresivo abandono del principio de mutualidad, (...) en otras palabras, que la mutualidad no constituye un elemento esencial, ni para la constitución, ni para el posterior funcionamiento de la sociedad cooperativa.» ${ }^{4}$ Esta afirmación, alude a una realidad objetiva: la

3 CANO LÓPEZ, A., «El complejo estatuto legal de la cooperativa en España: un apunte sobre algunas líneas de tendencia», en Internacionalización de las cooperativas. Aspectos jurídicos, económicos geográficos y sociológicos, Ed. Tirant Lo Blanch, Valencia, 2008, p. 75.

4 ĺdem. 
ampliación del objeto social de la cooperativa hacia la realización de actividades con terceras personas que no tengan la condición de socio.

Existe coincidencia en que la crisis de la mutualidad como elemento distintivo de la cooperativa, tiene fundamento en un reacomodo de la figura como única alternativa para garantizar su supervivencia: «Hoy la cooperativa como empresa debe poder enfrentarse en el mercado a otras empresas ordinarias. A tal fin la cooperativa debe contar con un mercado de desembocadura más amplio que el configurado tradicionalmente por su sola base social. $»^{5}$

Pareciera por tanto que las cooperativas han entrado en el juego competitivo del mercado. Pero coincidimos con PASTOR SeMPERE en que si bien capital y trabajo ya no se muestran antagónicos en la cooperativa, el primero es un medio para el fortalecimiento y la rentabilidad del segundo, «...se trata de un instrumento, no de un fin en sí mismo. Esta es la difícil traducción que el legislador debe realizar de esta realidad, si no se quiere vaciar de sentido la estructura organizativa de la sociedad cooperativa. .»6

b) Comprenden elementos sociales y elementos económicos, o sea la asociación y la empresa cooperativa.

Como hemos visto, para que exista una entidad cooperativa no basta con que un conjunto de personas asocien su esfuerzo al de las demás con el objetivo de satisfacer necesidades comunes, sino que es también imprescindible que procuren ese objetivo a través una empresa propia.

Sin embargo, ninguna empresa será realmente cooperativa si descuida los aspectos sociales inherentes a ella: este "espíritu cooperativo» que debe primar entre los asociados, se traduce en un conjunto de valores tradicionalmente reconocidos, practicados y promovidos por el movimiento cooperativo. En este sentido, la Declaración sobre la Identidad Cooperativa, adoptada por la Alianza Cooperativa Internacional (ACl) en el Congreso de su Centenario (1995) propugnó que «las cooperativas se basan en los siguientes valores: Auto ayuda, auto responsabilidad, democracia, igualdad, equidad y solidaridad. De acuerdo a la tradición de los fundadores, los asociados de las cooperativas sostienen los valores éticos de: Honestidad, apertura, responsabilidad social y preocupación por los demás. ${ }^{7}$

5 Pastor Sempere, C., «Empresa cooperativa y modelo constitucional: una aproximación», en Revista de Derecho de Sociedades, n. ${ }^{\circ}$ 17, 2001, p. 11.

6 ĺdem., p. 13.

$7 \mathrm{ACl}$, «Declaración Sobre la Identidad Cooperativa», Manchester, septiembre de 1995, reproducida y comentada por «El Hogar Obrero: Cooperativa de Consumo, Edi- 
Por tanto, son dos los elementos estructurales de toda entidad cooperativa: el elemento económico, o sea la empresa común, y el elemento social, la asociación de personas; ambos con un contenido y una forma de expresión que ameritarán su tipificación en una fórmula legal especial, encaminada a propiciar la realización de principios y valores presentes - de una u otra manera, incluso con carácter constitucional- en la generalidad de los ordenamientos jurídicos contemporáneos ${ }^{8}$.

c) Se rigen por determinados principios que definen su identidad: los principios cooperativos.

Una necesidad común que enfrentan todas las cooperativas es la de esclarecer en qué se diferencian de otras formas asociativas y de empresas, a fin de proyectar - a lo interno y lo externo - una identidad clara y distinta que pondere sus ventajas socioeconómicas. En este sentido, el movimiento cooperativo ha enarbolado una serie de principios que intentan delimitar la esencia de lo que debe ser una cooperativa, tanto en la expresión de su elemento económico como de su elemento social; aunque "...esos principios definen el modelo, a partir de ahí, cada concreta cooperativa es una realidad distinta... ${ }^{9}$, determinada por condicionantes históricas, culturales, socioeconómicas y políticas.

Lo que ha sido reconocido como la formulación originaria de los principios cooperativos, estaba implícita en los estatutos de la pionera cooperativa rochdoliana. ${ }^{10} \mathrm{~A}$ partir de las fluctuaciones de los intereses económicos y político prevalecientes en los diferentes contextos históricos, la $\mathrm{ACl}$ ha venido adaptando esos principios a las necesidades de las cooperativistas a nivel mundial, contribuyendo decisivamente a su «....alcance universal, al hacerlos aplicables a todos los tipos, tiempos y lugares... $»^{11}$. Los Congresos de París, 1937 y Viena, 1966, fueron momentos

ficación y Crédito Ltda.» en http://www.elhogarobrero1905.org.ar, consultada en diciembre de 2009.

8 Pensamos - entre otros - en la IGUALDAD, la EQUIDAD, la JUSTICIA SOCIAL, la SEGURIDAD SOCIAL Y ECONÓMICA, la SOLIDARIDAD, la RESPONSABILIDAD INDIVIDUAL Y COLECTIVA y la DEMOCRACIA en su más amplio sentido.

9 Trujilllo Diez, I. J., «El valor jurídico de los principios cooperativos. A propósito de la Ley 27/1999, de 16 de julio, de cooperativas», (resumen) en http://vlex.com/vid/ cooperativos-proposito-cooperativas-324086, consultado en diciembre 2009.

10 El gran mérito de los Pioneros de Rochadle no estuvo precisamente en la originalidad, sino en haber logrado - a través de ellos- codificar las reglas prácticas y teóricas existentes con anterioridad, marcando un antes y un después en el proceso de cooperativización.

11 Llobregat Hurtado, M. L., Mutualidad y empresa cooperativa, Ed. José M. Bosch, Barcelona, 1990, p. 16. 
medulares en este sentido; y más recientemente, de la Declaración sobre la Identidad Cooperativa, 1995, emanaron los nuevos y actuales principios cooperativos que a continuación reproducimos y analizamos:

«Primero: ASOCIACIÓN VOLUNTARIA Y ABIERTA

Las cooperativas son organizaciones voluntarias, abiertas a todas las personas capaces de utilizar sus servicios y dispuestas a aceptar las responsabilidades de asociarse, sin discriminaciones raciales, políticas, religiosas, sociales y de género.

Segundo: CONTROL DEMOCRÁTICO POR LOS ASOCIADOS

Las cooperativas son organizaciones democráticamente administradas por sus asociados, quienes participan activamente en la fijación de políticas y en la toma de decisiones. Los hombres y mujeres elegidos como representantes son responsables ante los asociados. En las cooperativas primarias los asociados tienen iguales derechos de voto (un asociado, un voto) y las cooperativas de otros niveles se organizan asimismo en forma democrática.

Tercero: PARTICIPACIÓN ECONÓMICA DE LOS ASOCIADOS

Los asociados contribuyen equitativamente a la formación del capital de su cooperativa y lo administran democráticamente. Por lo general, al menos una parte de ese capital es propiedad común de la cooperativa. Los asociados suelen recibir una compensación limitada, si acaso alguna, sobre el capital suscripto como condición para asociarse. Destinan los excedentes a todos o alguno de los siguientes fines: el desarrollo de la cooperativa, posiblemente mediante la constitución de reservas de las cuales una parte al menos debe ser indivisible; la distribución a los asociados en proporción a sus operaciones con la cooperativa y el apoyo a otras actividades aprobadas por los asociados.

Cuarto: AUTONOMIA E INDEPENDENCIA

Las cooperativas son organizaciones autónomas de auto ayuda administradas por sus asociados. Si intervienen en acuerdos con otras organizaciones, incluidos los gobiernos, o captan capital de fuentes externas, lo hacen en términos que aseguren el control por parte de los asociados y mantengan su autonomía cooperativa.

Quinto: EDUCACIÓN, CAPACITACIÓN E INFORMACIÓN

Las cooperativas brindan educación y capacitación a sus asociados, representantes elegidos, funcionarios y empleados, de manera que puedan contribuir efectivamente al desarrollo de ellas. Informan al público en general, particularmente a los jóvenes y a los líderes de opinión, acerca de la naturaleza y los beneficios de la cooperación.

Sexto: COOPERACIÓN ENTRE COOPERATIVAS

Las cooperativas sirven más eficientemente a sus asociados y fortalecen al movimiento cooperativo trabajando mancomunadamente a través de estructuras locales, nacionales, regionales e internacionales. 


\section{Séptimo: PREOCUPACIÓN POR LA COMUNIDAD}

A la vez que atienden las necesidades de sus asociados, las cooperativas trabajan en pro del desarrollo sustentable de sus comunidades mediante políticas aprobadas por aquéllos.»12

La importancia doctrinal de estos principios es innegable, al determinar cualidades esenciales que hacen diferente y valiosa a la empresa cooperativa frente a la empresa capitalista. A la vez, constituyen una guía cuyo espíritu integral se encamina a preservar la identidad y naturaleza revolucionaria del movimiento, con independencia del sistema socioeconómico en que se desenvuelva.

Su valor jurídico es también sobresaliente, pues al ser el cooperativismo un sistema diferente, que aspira a resolver los problemas con sujeción a reglas propias que no encuadran con exactitud dentro de las normas que regulan las relaciones socio-económicas prevalecientes, donde la ley cooperativa sea defectuosa, cabría subsanar la deficiencia a la luz de los principios del cooperativismo generalmente aceptados ${ }^{13}$. No en balde las leyes cooperativas de referencia establecen fórmulas como la siguiente:

«Artículo 6. Las cooperativas se regirán por las disposiciones de esta ley, sus normas reglamentarias y, en general, por el Derecho Cooperativo. Supletoriamente se regirán por el Derecho Común en cuanto fuera compatible con su naturaleza.

Derecho Cooperativo

Derecho Cooperativo es el conjunto de normas especiales, jurisprudencia, doctrina y práctica basadas en los principios que determinan y regulan la actuación de las organizaciones cooperativas y los sujetos que en ellas participan.»14

Pero, una valoración general de los principios cooperativos debe tener en cuenta que:

- Pese a que no son independientes unos de otros, sino que están unidos por tenues lazos, se defiende la idea de que las coope-

12 Alianza Cooperativa Internacional, «Declaración Sobre la Identidad Cooperativa», Manchester, septiembre de 1995, reproducida y comentada por «El Hogar Obrero: Cooperativa de Consumo, Edificación y Crédito Ltda.» en http://www.elhogarobrero1905. org.ar, consultada en diciembre de 2009.

13 Vid. García Müller, A., Instituciones de derecho cooperativo, social, solidario o de participación, Mérida, 2006, pp. 17-18.

14 Alianza Cooperativa Internacional para las Américas, «Ley Marco para las Cooperativas de América Latina», San José, 2009, en www.aciamericas.coop, consultada en julio de 2010. 
rativas no sean juzgadas en base a uno cualquiera de los principios, sino que se les debería evaluar por la manera en que se adhieren a ellos como un todo. ${ }^{15}$

- Su proclamación responde a un contexto en el que «...la economía de mercado ha extendido sustancialmente su impacto en todo el mundo... Estos cambios también han significado que la mayoría de las cooperativas deben hacer frente a una competencia mucho más intensa... Económicamente, (...) muchas cooperativas se han visto directamente enfrentadas a grandes empresas transnacionales, muchas de ellas con ventajas de capital y legislativas que no habían tenido antes. $\rangle^{16}$

- Sin embargo hoy estamos asistiendo, en palabras del Comité Económico y Social Europeo, "a una reestructuración a gran escala como consecuencia de la crisis en la economía europea. Las estrategias de reestructuración socialmente responsables son una condición esencial para evitar más quiebras y cierres de empresas, mantener y crear empleo y organizar el bienestar social mediante el impulso de la competitividad y el desarrollo local» ${ }^{17}$. En consecuencia, se debate la institución entre permanecer como instrumento de resistencia social o desnaturalizarse para ser absorbida en su plenitud por el sistema capitalista. La flexibilidad de los principios cooperativos es causa y resultado de esta disyuntiva.

\section{La cooperativa como figura jurídica}

La cooperativa, antes de encontrar cobija en una figura jurídica congruente con su esencia y objetivos, hubo de transitar por un espinoso camino de incomprensiones: "En las primeras épocas de su desarrollo, las cooperativas frecuentemente se adaptaron a las leyes vigentes sobre diversas asociaciones civiles o sobre sociedades mercantiles $\mathrm{y}$, en particular, a las disposiciones existentes en materia de mutualidades.... ${ }^{18}$.

15 Alianza Cooperativa Internacional, Los Principios Cooperativos para el siglo XXI (Documento de referencia acerca de la Declaración sobre la Identidad Cooperativa), publicado por El hogar Obrero: Cooperativa de Consumo, Edificación y Crédito Ltda., en http://www.elhogarobrero1905.org.ar, consultado en julio de 2010.

16 ldem.

17 Comité Económico y Social Europeo, Dictamen del sobre el tema «Cooperativas y reestructuración»(2012/C91/05):eu/LexUriServ/LexUriServ.do?uri=OJ:C:2012:191:0024 :0029:ES:PDF).

18 Kaplan de Drimer, A. y Drimer, B.: op cit., p. 473. 
Sin embargo, no transcurrió mucho tiempo para que los Estados se vieran persuadidos a dictar disposiciones legales específicas en las que se establecieran los caracteres básicos que distinguen la organización y el funcionamiento de las entidades cooperativas y, en consecuencia, durante la segunda mitad del siglo XIX se fueron aprobando, paulatinamente, disposiciones de este tipo en distintos países de Europa occidental (ya sea incluidas dentro de los códigos civiles, comerciales o en otros cuerpos legales) entre los que destacan Gran Bretaña, 1852; Alemania (Prusia) y Francia, 1867; Bélgica y Austria, 1873; Suiza, 1881 e Italia 1883. En esta región, la evolución de la cooperativa como figura jurídica ha estado hasta hoy íntimamente apegada al Derecho Mercantil19.

En América Latina se reconoce también que «la cooperación como hecho fundante de la vinculación asociativa en las entidades cooperativas, estuvo presente mucho antes de la recepción en las regulaciones legales del Estado» 20 , pues no es hasta entrado el siglo xx que comenzó a propiciarse el espacio para una legislación especial sobre cooperativas; el marco legal bajo el que funcionaban hasta entonces, resultó «...insuficiente y poco adecuado a la naturaleza propia de estas entidades... ${ }^{21}$. Actualmente en nuestra región, son más de 20 los países donde existe una legislación cooperativa específica 22 , que se pliega con fidelidad a los principios cooperativos proclamados por la $\mathrm{ACl}$, lo cual — con independencia de los matices propios de cada país - puede considerarse un rasgo distintivo de la legislación regional23. Sin embargo, ello no ha impedido que algunos, al contrastarla con la legislación europea, consideren que la utilización de la figura ha respondido más a fines político-ideológicos que a su carácter de empresa²4.

19 De preferencia confróntense las referencias al Reino Unido, Alemania, Francia e Italia en Gadea, E., Sacristán, F. y Vargas Vasserot, C., Régimen jurídico de la sociedad cooperativa del siglo XXI. Realidad actual y propuestas de reforma, Ed. Dykiston, Madrid, 2009, pp. 48 y ss.

20 Montenegro De Siquot, O. J. y De Gregorio, E., «El marco jurídico del cooperativismo y las entidades de economía social en la Argentina», en www.fundace.org.br/ cooperativismo/arquivos_pesquisa.../047-siquot.pdf consultados en diciembre de 2009, p. 6.

21 Cracogna, D., «Interculturalidad y Cooperativismo. Doctrina. Legislación. Experiencia», en Boletín de la Asociación Internacional de Derecho Cooperativo N. ${ }^{\circ} 41$, Facultad de Derecho, Universidad de Deusto, Bilbao, 2007, p. 40.

22 Vid. Compilación de ACl-Américas de la legislación cooperativa de América en www.aciamericas.coop/-Legislacion-Cooperativa-en-las,45-, consultada en octubre de 2010.

23 Vid. Cracogna, D., op. cit., pp. 38-41.

24 Cfr. Gadea, E., Sacristán, F. y Vargas Vasserot, C., op. cit., p. 51. 
A las alturas del siglo XXI se consolidan las legislaciones nacionales que reconocen —-formalmente- la identidad de la cooperativa, pero su naturaleza jurídica sigue siendo muy debatida, en tanto la flexibilidad de los principios cooperativos propicia su interpretación partidista por la doctrina, la jurisprudencia y el legislador, en cuyas manos descansa la responsabilidad de entender a la cooperativa con fidelidad a su originario espíritu transformador.

Una correcta delimitación de la naturaleza jurídica de una institución nos permite no solo determinar el régimen jurídico aplicable a ella (registro, competencia judicial, normas principales y supletorias a aplicar, etc.), sino además el papel que le corresponde jugar al interior del orden socioeconómico y político en que se deba desarrollar.

La idea general que sobre las cooperativas ya tenemos, nos lleva a sumergirnos - desde una perspectiva jurídica - en el complejo mundo de las asociaciones, donde existe multiplicidad de figuras, incluso con esencias diferentes. Con respecto a la cooperativa, el asunto es aún más complicado, pues la naturaleza jurídica de una institución se hace depender —en última instancia - del carácter público o privado que la misma posea, cuestión que en este caso no es clara.

Al respecto, el peruano TORRES Y TORRES LARA advierte que para la mayoría de los autores, no hay dudas de que la cooperativa es una persona jurídica de Derecho Privado, ya que su origen está en la voluntad de un grupo de individuos y no en el ius imperium, o sea que se rige por la voluntad de los socios sin interferencias del Estado, quienes además definen la oportunidad de su disolución y liquidación. ${ }^{25}$ Sin embargo, más adelante el propio autor señala que «...tenemos que admitir que la cooperativa no se comporta exactamente como la mayor parte de los entes del Derecho Privado. De ahí que algunos autores clasifican a la cooperativa como una persona jurídica de Derecho Social. Es decir en posición intermedia o singular entre las personas jurídicas de Derecho Privado y las del Público...» ${ }^{26}$.

Estos criterios demuestran una teoría - por joven - inacabada o en construcción que intenta despegarse — pues lo merece- de las viejas doctrinas liberales que hasta hoy han intentado dividir de forma dogmática lo público de lo privado, olvidando la dialéctica relación entre los componentes sociales. Por tanto, la cooperativa exige de un asidero jurídico que rompa con los viejos cánones y la guíe en sus revoluciona-

25 Vid. Torres y Torres Lara, C., Naturaleza jurídica de la cooperativa, Lima, 1983, en http://www.teleley.com/librosdederecho/7tc.pdf, consultado en septiembre de 2010, p. 114.

26 Idem., p. 115 
rios objetivos, salvando su autonomía e identidad sin que ello suponga olvidar sus responsabilidades sociales.

Con base en esta dicotomía, han surgido varias tesis que intentan explicar la naturaleza jurídica de la cooperativa, y que GADEA, SACRITÁN y VARGAS VASSEROT han agrupado en tres posiciones básicas: la que la considera una asociación; la que la considera una sociedad y la que la considera una categoría autónoma. ${ }^{27}$

Como es sabido, "la circunstancia de que la sociedad mercantil sea una especie del amplio género que es la asociación, no permite identificar ambas figuras... $\rangle^{28}$, pese a que tanto las primeras como las segundas existen gracias a una fusión de voluntades en torno a un fin común. Hasta hace pocos años, era plenamente aceptado que el elemento más seguro para lograr una distinción eficaz entre sociedades y asociaciones - en sentido estricto- radicaba en el fin lucrativo que acompañaba a las primeras - como requisito sine qua nom- y no a las segundas. Sin embargo, la creciente flexibilización de categorías jurídicas como las de sociedad y ánimo de lucro, han hecho mucho más compleja la tipificación de las cooperativas.

La postura que considera a las cooperativas como asociaciones ${ }^{29}$, proviene en mayor medida de los seguidores del cooperativismo ortodoxo y fue mayoritaria hasta hace pocas décadas. Su principal sustento descansa en el hecho - poco discutido hasta entonces - de que estas entidades carecen de ánimo de lucro, y que además tienen un fin social que justifica un mandato a la Administración Pública para su fomento, incluso desde los textos constitucionales ${ }^{30}$. En consecuencia, si las cooperativas carecen de uno de los elementos esenciales del concepto de sociedades (ánimo de lucro), no pueden ser más que parte del concepto genérico de asociaciones.

Se reconoce así a las cooperativas en las legislaciones de -entre otras - Venezuela, El Salvador y Costa Rica. Además, ACI-América en 2009 con la Ley Marco que intenta homogeneizar la legislación cooperativa del continente, asume -en su artículo 3- que: "Las cooperativas son asociaciones de personas que se unen voluntariamente para sa-

27 Vid. Gadea, E.; Sacristán, F. y Vargas Vasserot, C., op. cit., pp. 70-83.

28 Uría, R., Derecho Mercantil, Ed. Marcial Pons, Madrid, 2000, p. 166.

29 Resaltan en la doctrina, entre los seguidores de esta postura: Castán Tobeñas, J., Derecho civil español. Común y foral, T. IV, Ed. Reus, Madrid, 1985, p. 586 y DíezPicazo, L. y Guillón, A., Sistema de Derecho Civil, vol. II, Ed. Tecnos, 1999, p. 451.

30 V. gr. los actuales textos constitucionales de México, Nicaragua, Sao Tomé y Príncipe, Egipto, Bulgaria, Grecia, Chipre, Portugal, España, República Dominicana, Costa Rica, El Salvador, Honduras, Panamá, Colombia, Uruguay, Paraguay, Perú, Uruguay, Venezuela, Bolivia, Ecuador, etc. 
tisfacer sus necesidades económicas, sociales y culturales comunes por medio de una empresa de propiedad conjunta democráticamente gestionada. Son personas jurídicas privadas de interés social.»

Ante la posición anterior, hoy ganan terreno las tesis revisionistas, en defensa de la cooperativa como sociedad mercantil. Desde esta postura se distinguen tres vertientes que intentan justificarla, a saber:

- La interpretación amplia del ánimo de lucro: Sus defensores consideran que para que haya sociedad, es suficiente con que los socios persigan una finalidad de carácter patrimonial, susceptibles de aportarles una ventaja, ya sea con un incremento positivo de la riqueza; permitiendo el ahorro o evitando pérdidas. Sobre esta base, la cooperativa de consumo (destinada a aportar a los miembros condiciones ventajosas para la obtención de productos o servicios) y las cooperativas de producción (constituidas para favorecer las condiciones de trabajo), constituirían —en términos amplios- entidades lucrativas, y por tanto debe considerárseles sociedades.

- La interpretación amplia del concepto de sociedad: Con ella se niega que el ánimo de lucro sea un elemento de imprescindible presencia en la sociedad, y al reducirse las notas esenciales del concepto de sociedad tan solo al origen negocial y la índole común del fin promovido por todos los socios, se abarca dentro de los marcos del fenómeno societario, a otras figuras asociativas como la cooperativa. La profesionalidad en la actividad económica de la cooperativa, destinada a cubrir las necesidades de sus miembros, supone la estabilidad y la continuidad de su actuar, constituyendo un modelo de empresa que presenta afinidades básicas con el resto de las figuras empresariales que operan en el mercado, sin que de ello se derive - necesariamente - el ánimo de lucro, sino tan solo la exigencia de mantener rentabilidad o economicidad.

- La existencia de cooperativas lucrativas: Esta vertiente de pensamiento, para justificar la naturaleza societaria de la cooperativa, es mucho más radical, al considerar al ánimus lucrandi como uno de sus elementos constitutivos. Se fundamenta en la tendencia del Derecho positivo que, de sostener expresamente el fin no lucrativo de las cooperativas, ha pasado a omitir tal aspecto en sus definiciones, lo que se ha interpretado como una permisividad legal para que concurra este elemento. Esta flexibilidad - por omisión-, que acerca el régimen de las cooperativas al de las sociedades capitalistas, se aprecia también en el reconocimiento legal de socios puramente capitalistas y en la posibilidad de participación de la cooperativa en sociedades capitalistas. 
Con independencia de la concepción que se adopte para explicarlo, se reconoce a la cooperativa como sociedad en los ordenamientos jurídicos de Alemania, Bélgica, España, Francia, Italia, Canadá, EE.UU, Brasil, México, etc.

A nuestro criterio, sería ingenuo no percatarse de que las posturas revisionistas en pos del gradual acercamiento de la cooperativa a los dominios societarios, es expresión -en última instancia- de la dinámica absorbente del capital; a fin de cuentas el Derecho posee un carácter instrumental al servicio de los intereses políticos prevalecientes en cada contexto.

Por último, resalta la postura que considera a la cooperativa como una categoría autónoma. En ella no se acepta el carácter societario de la cooperativa por carecer de ánimo de lucro —elemento que se considera consustancial a la sociedad-y a su vez se niega que sean asociaciones propiamente dichas, por no perseguir un interés general o público, y además, por tener una serie de rasgos diferenciadores: «La cooperativa constituye una entidad de naturaleza especial. Se ha sostenido que no es comercial, ni civil. Por tanto el régimen y principios jurídicos que ordenan su funcionamiento y actividades son propios y específicos de estas entidades $»^{31}$.

Para aquellos que se afilian a esta vertiente teórica, ha sido importante el concepto de acto cooperativo ${ }^{32}$, el que ha servido no solo para sustentar la típica naturaleza de la cooperativa, sino además la existencia de un Derecho Cooperativo como rama autónoma.

Destaca en defensa de esta postura VICENT CHULÁ, para quién la cooperativa, tanto si la legislación lo reconoce formalmente como si no, es una institución sui generis, que no puede confundirse con la sociedad ni con la asociación, cuyo criterio refuerza ponderando la nece-

31 Montenegro de Siquot, O. J. y de Gregorio, E., op. cit., p.10

32 En sentido restringido, es considerado como el acto realizado por la cooperativa con un asociado en relación con el servicio o con la actividad propia del objeto social. De manera que son cooperativos aquellos actos que realizan las cooperativas y sus asociados, así como las cooperativas entre sí, con la finalidad de dar cumplimiento a los objetivos que persiguen en común, siempre que estén ajustados a los principios del cooperativismo. En sentido amplio, alcanzan bajo este espacio no solo las relaciones entre las cooperativas y sus asociados, o entre las cooperativas, sino que también incluye a los actos realizados entre las cooperativas y terceros no asociados, y siempre que esta última opere en cumplimiento de los objetivos que se ha propuesto (así lo entiende la legislación argentina y venezolana, entre otras). En suma, el negocio jurídico de la actividad cooperativa con notas singulares. Es una creación latinoamericana, que tuvo entre sus iniciales y principales precursores teóricos al mexicano Salinas Puentes en 1954, siendo acogido por primera vez por la ley brasileña n. ${ }^{\circ} 5764$ de 1971. Desde entonces ha operado como elemento armonizador de la legislación cooperativa en la región. 
sidad de una adecuada instrumentación legal de los principios cooperativos. ${ }^{33}$

El principal mérito de esta vertiente intermedia, acogida en las actuales legislaciones de Portugal, Argentina y Chile, es el de reconocer el carácter sui generis de la cooperativa: destaca sus rasgos, que si bien en ocasiones coinciden con los de las tradicionales asociaciones, y en otras con los de las sociedades, en su conjunto poseen la suficiente sustancia como para dotarlas de una identidad propia. Si bien nos mostramos partidarios de esta postura, sería ingenuo pensar que - con habitualidad - existen las condiciones objetivas y subjetivas para ser asumidas eficazmente por los ordenamientos jurídicos: el Derecho Cooperativo es un fenómeno en surgimiento y del que aún no existe plena conciencia; hasta tanto esto no ocurra, costará concretar una jurisdicción propia, con la aplicación supletoria de principios de una rama del Derecho específica preferentes a los de otras consolidadas y con tradición para asumir este papel.

Análisis aparte merece - por lo que representa en la historia jurídica cubana - la manera en que asumió y formuló la legislación soviética a la naturaleza jurídica de la cooperativa. En este sentido, debemos recordar ante todo que el Derecho que guió los pasos del socialismo real, fue resultado de una fuerte lucha de clase contra la propiedad privada sobre los medios de producción, en pos de la apropiación de éstos por obreros y campesinos; donde la fórmula legal para conseguirlos fue la proclamación del predominio casi absoluto — dependiendo del contexto histórico y geográfico del que se tratare - de la propiedad social socialista, expresada en la propiedad estatal y en la propiedad cooperativa sobre el patrimonio destinado a producir riquezas materiales y espirituales.

Este proceso de confrontación política tuvo alta incidencia para el campo de las Ciencias Jurídicas de otrora, en las que se confundieron categorías de la Economía y el Derecho, para dar paso a la concepción que define a la cooperativa como una forma de propiedad, y que a consideración de este autor, resultó reduccionista, pues ponderó el carácter colectivo del uso, disfrute y disposición del patrimonio cooperativo, en detrimento de sus intrínsecos principios de funcionamiento a lo interno y a lo externo. De esta forma se desvirtuó a la figura, sin que se obtuviera de ella los resultados esperados.

33 Vid. Vicent Chuliá, F., Compendio crítico de Derecho Mercantil, Ed. José M. Bosch, Barcelona, 1991, t. I, pp. 1019-1021 y también en este sentido —con apoyo en el ordenamiento jurídico peruano- Torres y Torres Lara, C., op cit., pp. 111-114. 
La cooperativa, para conseguir la socialización de la propiedad a que estuvo llamada, debe configurarse como un espacio asociativo, que propicie el desarrollo efectivo de un proceso de producción-apropiación de bienes y servicios en el que prime la equidad, la voluntariedad y la autonomía en su constitución y funcionamiento, al interior de un clima institucional que guíe su contribución a la solución de los problemas económicos y sociales de la comunidad en que se desarrolla.

No obstante, tengamos presente que «las instituciones jurídicas son lo que son por sus características intrínsecas y no por cómo se denominen ${ }^{34}$, en consecuencia, no porque el legislador adopte una $u$ otra de las variantes analizadas para definir la naturaleza jurídica de la cooperativa, evadirá la realidad concreta. La identidad cooperativa que el Derecho tendrá que legitimar, debe encontrar causa en el origen histórico de la figura y en los principios que materialmente la sostienen en cada contexto.

\section{La concepción jurídica de la cooperativa en el constitucionalismo cubano. Retos actuales}

En Cuba, el desarrollo jurídico -legal, científico y práctico- de la cooperativa ha sido escaso, lo cual ha estado determinado, en lo esencial, por circunstancias ideológico-políticas que exigen su estudio - primero- desde la rama rectora del ordenamiento jurídico, máxime cuando el país se adentra en un proceso de perfeccionamiento de su modelo socioeconómico en el que esta forma de gestión está llamada a ocupar un importante papel.

El primer antecedente constitucional de la figura se encuentra en el texto de 1940,35 que influido por el constitucionalismo social de la época la contempló como forma de empresa ${ }^{36}$ alternativa a las tradi-

34 Gadea, E., Sacristán, F. y Vargas Vasserot, C., op. cit., p. 72.

35 Los acontecimientos normativos sobre cooperativas más relevantes hasta 1940 son el Código de Comercio español de 1886 con su cláusula de aplicación excepcional a las cooperativas cuando abandonaban su carácter mutual (artículo 124) y la Ley de Asociaciones de 1889 que se hacía extensiva a ellas (artículo 1). En ambos casos se regulaba la figura como una cuestión incidental, sin que encontrara en estos predios legales un cauce enteramente congruente con su identidad.

36 Resalta lo adelantado de considerar a la cooperativa como empresa, teniendo en cuenta que la ACl lo hace por primera vez en 1995, con lo cual se manifiesta la diáfana intención constituyente de apartar a las cooperativas de las entidades caritativas o benéficas. Sin embargo, como veremos, esta voluntad constituyente no se prolonga en el constitucionalismo socialista. 
cionales (públicas y privadas) y como fuente de empleo en función del desarrollo local. ${ }^{37}$ Sin embargo, no se define como fenómeno asociativo en ninguna de sus manifestaciones, dejando el constituyente amplias prerrogativas a los poderes públicos para la concreción de su naturaleza jurídica y de su enrumbamiento social, lo que unido a la falta de voluntad política para garantizar el adecuado impulso de los mandatos constitucionales, dificultó el impulso para este sector.

Si bien después del triunfo revolucionario de 1959 la fórmula constitucional del 40 tocante a la cooperativa se preservó en la Ley Fundamental, la tendencia práctica y legal en la conformación de empresas rápidamente se inclinó hacia la forma estatal. La búsqueda de mecanismos de socialización de la propiedad, como vía para excluir «...la división de los hombres en poseedores de los medios de producción y desposeídos de ellos, y que las relaciones personales se basen en la colaboración y ayuda mutua» ${ }^{38}$, propósito marxista y genuinamente revolucionario, desembocó en la copia acrítica del modelo de economía soviético. Por ello, en marzo de 1968, prácticamente todos los medios útiles para la producción que no habían sido intervenidos pasaron a propiedad estatal, entendiéndose así terminado el proceso de socialización de la propiedad privada 39 .

Por consiguiente, la Constitución socialista cubana, tras su promulgación el 24 de febrero de 1976, estableció en el artículo 14 que: «En la República de Cuba rige el sistema socialista de economía basado en la propiedad socialista de todo el pueblo sobre los medios de producción y en la supresión de la explotación del hombre por el hombre».

El principal modo de expresión de este principio constitucional, que rectorea desde entonces el modelo económico cubano ${ }^{40}$, ha de hallarse en el precepto que consigna: "La propiedad estatal socialista, que es la propiedad de todo el pueblo...», para, taxativamente y en reglón seguido, definir el objeto de esta forma de propiedad con una amplísima gama de objetivos económicos de la que escapan, por excepción expresa, «...las tierras que no pertenecen a los agricultores pequeños o a cooperativas integradas por los mismos...».

37 Vid. Acta de la sesión de debate 69, del 4 de junio de 1940 en Lezcano y Mazon, A. M., Constitución de Cuba (con los debates sobre su articulado y transitorias, en la Convención Constituyente), T. II, Cultural S.A., La Habana, 1941, pp. 732 y ss.

38 Álvarez Tabío, F., Comentarios a la Constitución socialista cubana, Ed. Pueblo y Educación, La Habana, 1989, p. 84.

39 Vid. Casullera Arrate, R., «La Propiedad Personal en nuestra Constitución», en Revista Jurídica, n. ${ }^{\circ} 10$, La Habana, enero-marzo 1986, pp. 50-60.

40 No obstante, con la reforma constitucional de 1992 sufre una importante transformación al introducirse el adjetivo «fundamentales» para caracterizar a los medios de producción de propiedad social. 
De esta manera, poco espacio quedó para la conformación de cooperativas, que fueron constreñidas constitucionalmente por la propiedad estatal socialista. Se limitó su reconocimiento al artículo 20, que después de definir la propiedad de los agricultores pequeños, expresó el derecho de estos a asociarse entre sí, autorizándose la organización de cooperativas agropecuarias como otra forma de propiedad colectiva, junto a la estatal ${ }^{41}$.

Si bien el texto de este precepto sufrió algunas transformaciones a raíz de la Ley de Reforma Constitucional de julio de 1992, la definición de la cooperativa continúo limitándola al sector agropecuario de la economía ${ }^{42}$. No obstante, una valoración de las ideas esgrimidas durante el debate constitucional en el seno de la Asamblea Nacional del Poder Popular con motivo de la reforma, puede ilustrarnos — de primera mano- sobre el significado que se le atribuía a la figura en aquel complejo contexto ${ }^{43}$.

41 Texto (original) del artículo 20 de la Constitución socialista cubana de 1976: «El Estado reconoce la propiedad de los agricultores pequeños sobre sus tierras y otros medios e instrumentos de producción, conforme a lo que establece la ley.

Los agricultores pequeños tienen derecho a asociarse entre sí, en la forma y con los requisitos que establece la ley, tanto a los fines de la producción agropecuaria como a los de la obtención de créditos y servicios estatales.

Se autoriza la organización de cooperativas agropecuarias en los casos y en la forma que la ley establece. La propiedad cooperativa es una forma de propiedad colectiva de los campesinos integrados en ellas.

El Estado apoya la producción cooperativa de los pequeños agricultores, así como la producción individual, que contribuya al auge de la economía nacional.

El Estado promueve la incorporación de los agricultores pequeños, voluntaria y libremente aceptada por éstos, a los planes y unidades de producción agropecuaria.»

42 Artículo 20 de la Constitución socialista cubana de 1976 (actualizada): «Los agricultores pequeños tienen derecho a asociarse entre sí, en la forma y con los requisitos que establece la ley, tanto a los fines de la producción agropecuaria como a los de obtención de créditos y servicios estatales.

Se autoriza la organización de cooperativas de producción agropecuaria en los casos y en la forma que la ley establece. Esta propiedad cooperativa es reconocida por el Estado y constituye una forma avanzada y eficiente de producción socialista.

Las cooperativas de producción agropecuaria administran, poseen, usan y disponen de los bienes de su propiedad, de acuerdo con lo establecido en la ley y en sus reglamentos.

Las tierras de las cooperativas no pueden ser embargadas ni gravadas y su propiedad puede ser transferida a otras cooperativas o al Estado, por las causas y según el procedimiento establecido en la ley.

El Estado brinda todo el apoyo posible a esta forma de producción agropecuaria.»

43 Se conoció en Cuba como «período especial» a la primera mitad de la década de los noventa (fundamentalmente), pues tras la caída del Campo Socialista, con el que se mantenían fuertes lazos de dependencia, el país entra en una etapa de profunda crisis económica, política y social. 
Varias de las intervenciones fueron encaminadas a encontrar una definición adecuada de la cooperativa, a fin de lograr que los adjetivos que la acompañaran definieran con claridad su esencia y proyección socioeconómica. Existió consenso en que la preceptiva constitucional, al caracterizarlas, debía continuar exaltando su importancia; por eso el diputado y Presidente de los Consejos de Estado y de Ministros CASTRO Ruz (Fidel), insistió en "...lo de "avanzada y eficiente" porque hay que elogiarlas, moralmente hay que apoyar a las cooperativas. Es un paso de avance sin duda... $\rangle^{44}$, lo que estuvo reforzado por la voluntad constituyente de imponer al Estado el deber de brindarles todo el apoyo posible ${ }^{45}$.

Fue aceptado también con facilidad — de hecho no se discutió porque al parecer nadie lo dudó- que la cooperativa debía ser entendida -y por tanto definida constitucionalmente- como una forma de propiedad, rasgo que por sí mismo no es negativo, en tanto alude a la capacidad de la cooperativa de disfrutar de la titularidad de sus bienes. Pero, al concebirse en exclusivo como la naturaleza de la figura, evidencia - a juicio del autor - que se continuaba pensando la cooperativa con un criterio economicista a ultranza, que -en última instancia - reduce al mínimo sus muchas potencialidades. La cooperativa en el socialismo debe ser — como la propiedad — más que la fría y simplista suma de las facultades de administrar, poseer, usar y disponer de los bienes ${ }^{46}$.

Importante polémica generó el hecho de que se pretendiese -con el Proyecto de Reforma- conservar la definición de la cooperativa como una forma de propiedad colectiva, pues para algunos no resultaba suficiente para indicar el significado de la institución al interior de nuestro orden constitucional. En este sentido la diputada CASTRO ABRALDES expresó que: «...cuando se habla de propiedad social, existen diferentes formas. Cuando enmarcamos entre las formas de propiedad social la propiedad cooperativa, la identificamos como una propiedad colectiva. En la literatura económica (...) a este tipo de propiedad cooperativa nuestra le ponemos el apellido de propiedad colectiva socialista, porque cuando se explica el capitalismo se da el nivel de socialización que está alcanzando este modo de producción [por tanto] pienso

44 Acta contentiva de la discusión del Proyecto de Ley de Reforma Constitucional; Décimo Período Ordinario de Sesiones, Tercera Legislatura de la Asamblea Nacional del Poder Popular; días 10, 11 y 12 de julio de 1992; p. 185.

45 Vid. Artículo 20 de la Constitución socialista cubana de 1976 (actualizada).

46 ldem. 
que la terminología más adecuada para utilizar aquí constitucionalmente es la de "propiedad colectiva socialista" ${ }^{47}$

Sobre esta misma cuestión ya había precisado el diputado y Presidente de los Consejos de Estado y de Ministros Castro Ruz (Fidel), que no era suficiente con que se declarara a la cooperativa como "una forma avanzada y eficiente de propiedad colectiva», pues esta definición genérica también serviría a la sociedad anónima y no existía la intención de confundirlas. ${ }^{48}$

Al respecto - y tras solicitarse la intervención de un especialista- el diputado Rodríguez RodríGUez aclaró que «...la forma colectiva puede ser socialista o puede no ir inclinada al socialismo». Ante esta precisión, el Presidente de la Asamblea le pregunta al propio diputado: «¿Entonces no puede ser propiedad socialista?» —y éste responde— «No puede ser "propiedad socialista" porque no siempre la forma colectiva va dirigida al socialismo». Seguidamente el diputado y Presidente de los consejos de Estado y de Ministros CASTRO Ruz (Fidel) indaga: "¿Y tú cómo pondrías, "propiedad colectiva socialista" o "propiedad socialista"?». A lo cual responde RodríGuez RodríGuez: " "Propiedad colectiva" más bien». ${ }^{49}$

El criterio de no incluir el adjetivo de socialista para caracterizar a la propiedad cooperativa, también se defendió por el diputado RamíREZ CRUZ, para quién «...el concepto de propiedad socialista es la propiedad de todo el pueblo y ésta [la cooperativa] es una propiedad de grupo, es decir, no es una propiedad de toda la sociedad; (...) por eso creo que el nombre más correcto es "propiedad colectiva" y no "socialista" 50 .

En busca de consenso, el Presidente de la Asamblea propone sustituir la fórmula original de "forma de propiedad colectiva», no ya por la de "forma de propiedad colectiva socialista», sino por la que definitivamente se aprobó: "forma de producción socialista» 51 , lo que a consideración del autor constituyó una ambigüedad innecesaria, en tanto es resultado de un fuerte desconocimiento de la naturaleza y cualidades que definen a la cooperativa.

Este debate y su resultado, evidenciaron que el pensamiento de los diputados ante aquella realidad concreta — demandante de flexibilidad

47 Acta contentiva de la discusión del Proyecto de Ley de Reforma Constitucional, Décimo Período Ordinario de Sesiones, Tercera Legislatura de la Asamblea Nacional del Poder Popular, días 10, 11 y 12 de julio de 1992, pp. 188-189.

48 vid. ĺdem., p. 185.

49 Ibídem., p. 186.

50 Ibídem., p. 187.

51 Ibídem., p. 188. 
y dinamismo - seguía estando constreñido por los esquemas originales. Se continuó relegando a la cooperativa a un plano inferior al de la propiedad socialista, la que a su vez se mantuvo reducida a la propiedad estatal, entendida como la propiedad de todo el pueblo y - por tanto- la única manifestación de la propiedad social. La propiedad «...es una expresión de la naturaleza y del carácter de las relaciones sociales de producción; si estas son de explotación y dominación de una clases por otras la propiedad refleja, en sus estructuras y en sus funciones, esta realidad; si por el contrario, las relaciones sociales de producción lo son de cooperación, así será entonces la forma de propiedad que les corresponda» 52 .

Por tanto, nada obsta para considerar que en el modelo cubano la cooperativa es - también - una forma de propiedad socialista, aunque -obviamente- no basta con declararla como tal en el texto constitucional, sino que además corresponde al ordenamiento jurídico cubano guiar el contenido de las relaciones de producción y el desarrollo de las fuerzas productivas hacia los niveles de ascenso necesarios para que esa forma de apropiación sea —en verdad-socialista. Se trata de una aspiración — sin que existan razones para no reconocerlo- que como cualquier otra debe ser conquistada.

Con respecto al carácter agropecuario o no de la cooperativa, las interpretaciones doctrinales al texto constitucional cubano de 1976 habían estado divididas, pese a que éste — desde entonces - las caracteriza como instituciones agropecuarias: Para algunos «la Constitución reconoce a la cooperativa como una propiedad agraria, sin hacerla extensiva a ningún otro tipo de explotación económica» ${ }^{53}$, viéndose así - en la definición constitucional de la cooperativa - un límite para la expansión legal de la figura a otros sectores de la economía; para otros, en cambio, "la enumeración constitucional de las formas de propiedad no es taxativa, por lo cual es factible que la ley establezca la autorización para otras modalidades o posibilidades de la propiedad cooperativa» ${ }^{54}$.

Al respecto, durante el proceso de discusión y aprobación del Proyecto de Reforma Constitucional de 1992, el diputado y Presidente de los Consejos de Estado y de Ministros CASTRO Ruz (Fidel) alertó: «...toda la perestroika empezó hablando de cooperativas, de cooperativas de servi-

52 Azcuy, H., "Análisis de la Constitución cubana», en Revista Papeles de la FIM, n. ${ }^{\circ}$ 14, Madrid, 2000, p. 52.

53 ldem., p. 54.

54 Vega Vega, J., Derecho Constitucional revolucionario en Cuba, Ed. Ciencias Sociales, La Habana, 1988, p. 159. 
cios, cooperativas de tiendas, cooperativas de negocio, y todo camino del capitalismo a toda velocidad. No debemos olvidarnos de esos otros pequeños riesgos de que parezca exaltada demasiado la propiedad cooperativa. Creo que debiéramos distinguir un poco y decir "de propiedad cooperativa agrícola", para distinguirla frente a cualquier tendencia de querer generalizar el concepto de la cooperativa, porque si funciona en la agricultura, debemos decir "forma de propiedad cooperativa agrícola" ${ }^{55}$.

Justificada era la prudencia, pues pervivía el fantasma del derrumbe del campo socialista y resonaban los retóricos augurios que, desde afuera del país, aseguraban que el régimen socioeconómico y político cubano se revertiría. Este entramado de circunstancias negativas, creaba una coyuntura compleja para implementar — sin renunciar al socialismo, pero con las dosis de experimentación necesarias- los imprescindibles cambios que nuestro modelo económico requería.

Sin embargo, no debemos pensar que algún elemento no sería de factible implementación en nuestro país tan solo porque formó parte de la perestroika ${ }^{56}$. Es importante dejar claro que la expansión del sector cooperativo no es, en sí misma, un factor de riesgo para la continuidad del socialismo: ningún fenómeno puede juzgarse bien fuera de su contexto, cada circunstancia debe valorarse con objetividad y sentido del momento histórico; solo entonces cabría decidir si es o no factible la instrumentación de cooperativas en algún sector de la economía nacional diferente al agropecuario.

Las concepciones que sobre las cooperativas venimos analizando han primado en Cuba - al menos- durante las últimas cuatro décadas, por lo que su reconocimiento en el texto constitucional vigente presenta - aún - un grupo de limitaciones jurídicas que obstaculizan el aprovechamiento óptimo de sus potencialidades, entre las que destacan:

55 Acta contentiva de la discusión del Proyecto de Ley de Reforma Constitucional, Décimo Período Ordinario de Sesiones, Tercera Legislatura de la Asamblea Nacional del Poder Popular, días 10, 11 y 12 de julio de 1992, pp. 189-190.

56 De hecho, no sería acertado culpar del descalabro a que conllevó la nueva política de reestructuración económica tan solo a sus precursores, debemos recordar que ella estuvo precedida de varias décadas plagadas de errores de todo tipo: el proceso de colectivización forzosa de los campesinos; el terror político desarrollado por Stalin; la ausencia de un auténtico centralismo democrático como método sistemático de gobierno, la separación cada vez mayor del Partido —y sobre todo su máxima direcciónde las masas populares; la burocratización del trabajo político ideológico; el formalismo; el oportunismo y el dogmatismo; son solo algunos de ellos. Vid. Rodríguez García, J. L., «La perestroika en la economía soviética 1985-1991», en Revista Internacional Marx Ahora, n. ${ }^{\circ} 22$, La Habana, 2006, p. 53. 
- Se regula como parte indisoluble del sector agropecuario de la economía, lo que ha generado que su desarrollo jurídico - legal y científico- además de escaso, haya sido materia exclusiva del Derecho Agrario.

- El derecho de asociarse en cooperativas solo se reconoce a los agricultores pequeños y no a otros sectores del pueblo trabajador ${ }^{57}$.

- No se sientan pautas generales suficientes para el control de la cooperativa por sus asociados, pues si bien se establece que ellas "...administran, poseen, usan, y disponen de los bienes de su propiedad... ${ }^{58}$, la participación de los miembros en la empresa económica común que ella supone, siempre será más compleja que el mero ejercicio de facultades sobre bienes.

- Los fines para los que se concibe están expresamente establecidos: «...producción agropecuaria...» y «...obtención de créditos y servicios estatales... $\gg^{59}$, cuando podrían ser mucho más heterogéneos e igual de consecuentes con la esencia socialista del diseño constitucional, por lo que su formulación taxativa y cerrada no es aconsejable.

- En cuanto a las relaciones entre cooperativas no se promueven, haciéndoseles depender exclusivamente del apoyo estatal. 60

57 Si bien en 1976 podía resultar contradictorio el reconocimiento constitucional del derecho de asociarse en cooperativas a otros trabajadores diferentes a los agricultores pequeños, dado el hecho de que los primeros, a diferencia de los segundos, no contaban con medios de producción de propiedad individual, esta lógica ya hoy carece de fundamento, pues los medios e instrumentos de trabajo que la Constitución cubana reconoce en su artículo 21, como parte de la propiedad personal, se han convertido -a través del trabajo por cuenta propia - en genuinos medios de producción. Además, la forma cooperada de gestión puede instrumentarse conservando la propiedad estatal sobre los medios fundamentales de producción, pero cediendo su uso y disfrute a los trabajadores (V. gr. Unidades Básicas de Producción Cooperativa, implementadas por el Decreto Ley 142 de 20 de septiembre de 1993, a través de las cuales se convirtió a los obreros agrícolas en usufructuarios de la tierra estatal y propietarios del resto de los medios de producción necesarios para su explotación).

58 Artículo 20 - 3er. párrafo— de la Constitución de la República de Cuba (actualizada).

59 Esta formulación empleada por el artículo 20 de la Constitución cubana (actualizada), es causa para que en Cuba no exista una Ley de Cooperativas, sino una "Ley de Cooperativas de Producción Agropecuaria y de Créditos y Servicios», Ley n. ${ }^{\circ} 95$ del 2 de noviembre de 2002.

60 Esta colaboración entre cooperativas pudieran alcanzar, incluso, dimensiones internacionales en el marco la Alianza Bolivariana para los Pueblos de Nuestra América (ALBA): nace como propuesta alternativa al Área de Libre Comercio de las Améri- 
- También se requiere precisión sobre el grado de autonomía e independencia de las cooperativas para planificar y orientar sus estrategias de desarrollo con respecto, sobre todo, a los órganos de poder del Estado (a todos los niveles territoriales).

- Sobre las líneas de proyecciones de estas empresas para con la sociedad en general es pertinente colocar exigencias, ya que la cooperativa - más en un sistema socialista - tendrá siempre que estar ocupada en garantizar el desarrollo sustentable de la comunidad en que se desenvuelve.

- La importancia de la educación cooperativa para la viabilidad de forma de gestión amerita un pronunciamiento constitucional, induciendo para su práctica tanto a las propias cooperativas, como al aparato institucional del Estado y a la comunidad en general.

- Se reduce la naturaleza jurídica de la institución, en detrimento de sus intrínsecos principios de funcionamiento a lo interno y a lo externo, a forma de propiedad, limitándose su valor como espacio asociativo de alto contenido social.

A tono con estas dificultades, se impulsa hoy en el país una reestructuración del modelo socioeconómico: los hechos demuestran la necesidad de aligerar la maquinaria administrativa, desconcentrar, descentralizar, aumentar la autonomía local y, en sentido general, terminar con las manifestaciones de sobreprotección o paternalismo estatal en el intento - aún fallido- de satisfacer las demandas sociales básicas. Por ello, se ha planteado desde la dirección del Estado que «...estamos en el deber de (...) transformar concepciones y métodos que fueron los apropiados en su momento, pero han sido ya superados por la propia vida» ${ }^{61}$.

Por consiguiente, en abril de 2011 el VI Congreso del Partido Comunista de Cuba aprobó los Lineamientos de la Política Económica y

cas (ALCA), de un Documento firmado entre Cuba y Venezuela, el 14 de diciembre de 2004, al que hoy se suman varios países de la región; se caracteriza por potenciar el desarrollo endógeno, la complementación, la cooperación, la solidaridad y el respeto a la soberanía de los países miembros. [Vid. BossI, F.R.: "¿QUÉ ES EL ALBA? Construyendo el ALBA desde los Pueb/os», en http://www.alianzabolivariana.org/modules.php?name= News\&file=article\&sid=470, consultado el 20 de junio de 2012]. Puede consultarse también el portal http://www.alianzabolivariana.org/

61 Discurso pronunciado por el entonces Primer Vicepresidente de los Consejos de Estado y de Ministros, General de Ejército, Raúl Castro Ruz, en el acto central con motivo del Aniversario 54 del asalto a los cuarteles Moncada y Carlos Manuel de Céspedes, en la Plaza de la Revolución Mayor General Ignacio Agramonte Loynaz de la ciudad de Camagüey, el 26 de julio del 2007, en www.cubadebate.cu, consultado en octubre de 2009. 
Social del Partido y la Revolución62, con el objetivo de sentar las pautas necesarias para conducir el proceso de actualización del modelo socioeconómico socialista en el país. ${ }^{63}$

Si bien estos Lineamientos carecen de fuerza legal, no hay dudas de que el papel de vanguardia y dirección política que le asigna el artículo 5 de la Constitución socialista cubana de 1976 al Partido Comunista de Cuba64, así como la legitimidad histórica que caracteriza a la organización, convierten sus decisiones en fuente material para la creación del Derecho. Por ello, recién se ha aprobado el Decreto-Ley n. ${ }^{\circ} 305$ de 11 de diciembre de 2012, "DE LAS COOPERATIVAS NO AGROPECUARIAS»65, que habrá de fungir como plataforma legal — de carácter experimental66 — para ordenar las experiencias pilotos de este tipo.

De esta forma se hace palpable la voluntad política de incrementar el aprovechamiento de la cooperativa como una forma de gestión aconsejable al interior del modelo socialista que intentamos rediseñar, en tanto constituye un espacio asociativo regido por principios que ponderan la solidaridad frente al individualismo, la democracia ante la explotación, y la participación en lugar del paternalismo y/o el determinismo; todo ello en un contexto nacional en el que la disponibilidad de trabajadores resultado de la descongestión del sector estatal67 (caracte-

62 Vid. VI Congreso del Partido Comunista de Cuba, Lineamientos de la Política Económica y Social del Partido y la Revolución, 18 de abril de 2011, en www.cubadebate. cuwp-contentuploads201105folleto-lineamientos-vi-cong.pdf, consultado el 15 de junio de 2011.

63 Para consultar un análisis detallado de la trascendencia de los Lineamientos para la regulación jurídica de la cooperativa en Cuba Vid. Rodríguez Musa, O., «Socialismo, Cooperativismo y Derecho. Dialéctica necesaria para la actualización del modelo económico cubano», Boletín n. ${ }^{\circ}$ 46, año 2012, Asociación Internacional de Derecho Cooperativo, Universidad de Deusto, España, pp. 93-102.

64 Art. 5 de la Constitución socialista cubana de 1976 (actualizada): «El Partido Comunista de Cuba, martiano y marxista-leninista, vanguardia organizada de la nación cubana, es la fuerza dirigente superior de la sociedad y del Estado, que organiza y orienta los esfuerzos comunes hacia los altos fines de la construcción del socialismo y el avance hacia la sociedad comunista.»

65 Vid. Gaceta Oficial n. ${ }^{\circ} 053$ Extraordinaria Decreto-Ley n. ${ }^{\circ} 305$ de 11 de diciembre de 2012, en la que también se incluyen, entre otras disposiciones relativas a la materia, el Decreto N. ${ }^{\circ} 309$, Reglamento de las coooperativas no agropecuarias de primer grado.

66 Vid. Segundo POR CUANTO y Artículo 1 del Decreto-Ley n. 305 de 11 de diciembre de 2012.

67 Las proyecciones de la economía para el periodo 2011-2015, previeron en el plan del año 2011, la reducción de más de 500000 trabajadores en el sector estatal, donde el exceso de plazas sobrepasa el millón. Vid. Central DE Trabajadores DE CuBA: Pronunciamiento del 13 de septiembre 2010, en www.cubadebate.cu/noticias/2010/09/13/reducira-cubamedio-millon-de-plazas-en-el-sector-estatal, consultado el 28 de octubre de 2010. 
rizados comúnmente por el desasosiego, el aislamiento y la falta de pericia) y la flexibilización del trabajo por cuenta propia (que ha incluido la contratación de mano de obra entre particulares ${ }^{68}$ ), parecen necesitar un asidero socializador hacia el cual fluir.

Es válido reconocer que el nuevo Decreto-Ley parece superar el criterio reduccionista que la asume a la cooperativa como forma de propiedad, ofreciendo como sustento para su funcionamiento, un conjunto de principios avanzados y coincidentes —en gran medidacon los universalmente reconocidos. Sin embargo, se continúa parcelando la legislación cooperativa cubana ${ }^{69}$ y persisten ambigüedades en la concepción jurídica de la institución, toda vez que - con probables prejuicios sobre las sociedades - la define en su artículo 1 como una organización y, más adelante (artículo 14), exige su inscripción en el Registro Mercantil; todo lo cual provoca efectos lesivos para su identidad.

A lo anterior se une la incertidumbre generada por el artículo 3 de la norma objeto de análisis pues, al delimitar el marco legal de las cooperativas no agropecuarias expresa que a ellas corresponden «...de forma supletoria las disposiciones legales que les resulten aplicables». En este sentido ¿acaso resultará aplicable el Código Civil, aludido en el primer POR CUANTO del Decreto-Ley y supletorio por excelencia o, en correspondencia con su inscripción en el Registro Mercantil, el Código de Comercio?. La respuesta a esta interrogante toca la naturaleza jurídica de la figura, cuya determinación no es sencilla en el ordenamiento jurídico cubano.

Por tanto, es necesario que al impulsarla como fuente de empleo y como expresión del derecho a la libre asociación de los trabajadores para la satisfacción de intereses individuales y colectivos, se asiente sobre presupuestos sólidos definidos constitucionalmente, de manera que — llegado el momento— se erijan como pautas para la concreción legal definitiva y unificadora de la materia.

68 Solo en la provincia de Pinar del Río, se han otorgado 1799 licencias para contratar fuerza de trabajo (12.11\% del total de licencias otorgadas) [Vid. García Pérez, C., «El Sistema Empresarial estatal cubano», conferencia de actualización impartida en el Diplomado de Administración Pública para Cuadros del Partido, el Estado y el Gobierno en la Provincia de Pinar del Río, 2. ${ }^{a}$ edición, 13 de mayo de 2012.]; lo que contrasta con el principio constitucional (art. 14) de «supresión de la explotación del hombre por el hombre».

69 Cfr. «Ley de Cooperativas de Producción Agropecuaria y de Créditos y Servicios», Ley n. 95 de 2 de noviembre de 2002; "Sobre las Unidades Básicas de Producción Cooperativa», Decreto-Ley n. ${ }^{\circ} 142$ de 20 de septiembre de 1993 y «De las Cooperativas no Agropecuarias», Decreto-Ley n. ${ }^{\circ} 305$ de 11 de diciembre de 2012. 
Pero - como hemos visto- difícil será que en las actuales condiciones, en las que se reduce la concepción jurídica de la cooperativa a la de forma de propiedad (agraria), el magno texto pueda guiar de manera efectiva la implementación legal de la figura hacia una perspectiva integral, como asociación democrática viable para propiciar el desarrollo económico y social en cualquier sector de la economía nacional (tanto es así que el nuevo Decreto-Ley no la refiere en sus POR CUAN$\left.\operatorname{TOS}^{70}\right)$.

En este definitorio proceso de transformaciones que hemos emprendido ha de ocupar la Constitución — previo estudio y modificación de su preceptiva - el lugar que le corresponde, aportando —al legislador ordinario- base y cima, cauce y límite ${ }^{71}$ y fungiendo como garantía para la preservación de la esencia socialista de los fundamentos del sistema socioeconómicos que refrenda, cuyo carácter irrevocable figura en la propia Constitución —por iniciativa popular- desde el año $2002^{72}$.

\section{Conclusiones}

A partir de lo anterior podemos concluir que:

1. Las cooperativas poseen una identidad propia, determinada por un grupo de cualidades que las convierten en una alternativa viable para cualquier sector de la economía, con independencia del contexto socioeconómico en que se desarrollen. Dentro de estas cualidades destacan: a) son entidades integradas por grupos de personas con el objetivo de atender a sus propias necesidades socioeconómicas, sobre la base del esfuerzo propio y la ayuda mutua; b) comprenden elementos sociales y elementos económicos, o sea la asociación y la empresa cooperativa; c) se rigen por determinados principios que las distinguen de otras formas asociativas y de empresa, sobre todo de las capitalistas.

70 No obstante, es oportuno aclarar que si bien no ofrece la Constitución socialista cubana una regulación de la cooperativa suficiente para guiar con éxito su expansión y evolución jurídica en la nueva coyuntura, no ha de entenderse que ella resulta contraria a alguno de los fundamentos básicos del magno texto. Para una profundización al respecto Vid. Rodríguez Musa, O., La cooperativa como figura jurídica. Perspectivas constitucionales en Cuba para su aprovechamiento en otros sectores de la economía nacional además del agropecuario, Ed. Dikinson SL., Madrid, 2012, pp. 69-79.

71 Vid. Prieto Valdés, M, «Las Funciones de la Constitución», Revista Jurídica, año 5, n. ${ }^{\circ}$ 9, enero-junio 2005, MINJUS, La Habana, pp. 38-46.

72 Vid. Ley de Reforma Constitucional del 26 de junio de 2002 (Gaceta Oficial Extraordinaria del 16 de julio de 2002). 
2. Es vital el papel ordenador y canalizador del Derecho en el proceso dialéctico de adecuación de la cooperativa a los diferentes contextos, propiciándole marcos legales que le permitan el desarrollo de sus potencialidades socioeconómicas. No obstante, algunas tendencias jurídicas se separan de su esencia e identidad provocando su desnaturalización.

3. En Cuba, la dinámica del actual contexto exige a la cooperativa jugar un papel trascendental; sin embargo, la vigente concepción constitucional de la institución resulta reduccionista, pues presenta un grupo de limitaciones que obstaculizan su óptimo aprovechamiento. Por tanto, para que la Constitución pueda guiar de manera efectiva la implementación legal de la figura hacia una perspectiva integral, es necesario que el perfeccionamiento de su regulación encuentre sustento en la identidad cooperativa.

\section{Bibliografía}

Álvarez Tabío, F.: Comentarios a la Constitución socialista cubana, Ed. Pueblo y Educación, La Habana, 1989.

AzcuY, H.: "Análisis de la Constitución cubana», en Revista Papeles de la FIM, n. ${ }^{\circ}$ 14, Madrid, 2000, pp. 11-144.

CANo LóPEZ, A.: «El complejo estatuto legal de la cooperativa en España: un apunte sobre algunas líneas de tendencia», en Internacionalización de las cooperativas. Aspectos jurídicos, económicos geográficos y sociológicos, Ed. Tirant Lo Blanch, Valencia, 2008, pp. 71-88.

CARELLO, L.A.: «El emprensarialismo cooperativo, el cambio de los principios», en Congreso de Cooperativismo, Universidad de Deusto, Bilbao, 1988, pp. 183-204.

Carranza Valdés, J., Gutiérrez Urdaneta, L. y Moreal González, P.: «Cuba: la reestructuración de la economía. Una propuesta para el debate», en PÉREZ Hernández, L. y Prieto Valdés, M. (compiladoras): Temas de Derecho Constitucional cubano, Ed. Félix Varela, La Habana, 2004, pp. 65-74.

Castán Tobeñas, J.: Derecho civil español. Común y foral, t. IV, Ed. Reus, Madrid, 1985.

Castro Ruz, F.: La Historia me Absolverá, edición anotada por Álvarez Tabío, P. y Alonso Fiel, G., Ed. Oficina de Publicaciones del Consejo de Estado y Ed. Pueblo y Educación, La Habana, 2005.

— «Regalo de reyes» (Reflexión), La Habana, 14 de enero de 2008, en www. cubadebate.cu/reflexiones-fidel/2008/01/14/regalo-reyes, consultado en octubre de 2010.

Casullera Arrate, R.: «La Propiedad Personal en nuestra Constitución», en Revista Jurídica, n. ${ }^{\circ} 10$, enero-marzo 1986, pp. 50 y ss. 
CRACOGNA, D.: «Interculturalidad y Cooperativismo. Doctrina. Legislación. Experiencia», en Boletín de la Asociación Internacional de Derecho Cooperativo, n. ${ }^{\circ} 41$, Facultad de Derecho, Universidad de Deusto, Bilbao, 2007, pp. 33-46.

— «La Legislación Cooperativa en el mundo de hoy», en http://www.neticoop. org.uy/article188.html, consultado en diciembre de 2009.

- «Los principios cooperativos en el Proyecto de Ley Marco para las Cooperativas de América Latina», en Boletín de la Asociación Internacional de Derecho Cooperativo, n. 23 y 24, Facultad de Derecho, Universidad de Deusto, Bilbao, 1995, pp. 141-154.

Díez-Picazo, L. y Guillón, A.: Sistema de Derecho Civil, vol. II, Ed. Tecnos, 1999.

DIVAR, J.: «El Derecho comparado cooperativo en Europa», en Anuario de Estudios Cooperativos, Universidad de Deusto, Bilbao, 1988, pp. 111-120.

- «La Asamblea Social y la soberanía jurídica en las cooperativas», en Anuario de Estudios Cooperativos, Universidad de Deusto, Bilbao, 1988, pp. 27-30.

- «Transcooperativismo y perestroika: análisis de la nueva Ley de Cooperativas de la URSS», en Anuario de Estudios Cooperativos, Universidad de Deusto, Bilbao, 1989, pp. 155-164.

- Globalización y Democracia, Ed. Dykinson, Madrid, 2005.

Duque Domínguez, J.F.: «Constitución Económica y Derecho Mercantil», en La Reforma de la Legislación Mercantil, Ed. Civitas, Madrid, 1979, pp. 63-110.

- «Principios cooperativos y experiencia cooperativa», en Congreso de Cooperativismo, Universidad de Deusto, Bilbao, 1988, pp. 89-118.

Escalona Reguera, J.: «En torno a la Ley de Reforma Constitucional», en Revista Cubana de Derecho, n. ${ }^{\circ}$ 8, La Habana, 1992, pp. 3-18.

FERnÁndez Peiso, L.A.: El fenómeno cooperativo y el modelo jurídico nacional. Propuesta para la nueva base jurídica del cooperativismo en Cuba, tesis presentada en opción al grado científico de Doctor en Ciencias Jurídicas, Cienfuegos, 2005.

— «Estudios jurídicos del cooperativismo», en Anuario del Centro de Investigaciones Jurídicas, 2003, La Habana, pp. 187-210.

GADEA, E.: Evolución de la legislación cooperativa en España, Consejo Superior de Cooperativas de Euskadi, 1999.

GadeA, E., SACRISTÁn, F. y VARgas VAsSerot, C.: Régimen jurídico de la sociedad cooperativa del siglo XXI. Realidad actual y propuestas de reforma. Ed. Dykiston, Madrid, 2009.

García Müler, A.: "Las grades tareas del cooperativismo venezolano actual», en Boletín de la Asociación Internacional de Derecho Cooperativo, n. ${ }^{\circ} 41$, Facultad de Derecho, Universidad de Deusto, Bilbao, 2007, pp. 111-122.

- Instituciones de derecho cooperativo, social, solidario o de participación; Mérida, 2006.

Garrido FAlla: El modelo económico en la constitución española, Madrid, 1984.

Gómez, L.: La Alianza Cooperativa Internacional, su desarrollo como institución $y$, en especial, como instrumento trasformador de la sociedad, tesis doctoral publicada por el Consejo Superior de Cooperativas de Euskadi con la colaboración de la Universidad de Deusto y la Universidad del País Vasco, 1997. 
Gromoslav Mladenatz: Historia de las doctrinas cooperativas, Ed. Intercoop, Buenos Aires, 1969.

HeRnández R. y Pañellas D.: "Sobre la transición socialista en Cuba: un simposio», en Revista Temas, n. ${ }^{\circ}$ 50-51, abril-septiembre, La Habana, 2007, pp. 126-162.

Hernández Ruiz, J.A. y Pérez Hernández, L.: «Apuntes sobre la propiedad desde un punto de vista constitucional», en Pérez Hernández, L. y Prieto Valdés, M. (compiladoras): Temas de Derecho Constitucional cubano, Ed. Félix Varela, La Habana, 2004, pp. 91-102.

Kaplan de Drimer, A. y Drimer, B.: Las cooperativas. Fundamentos-Historia-Doctrina, Ed. Intercoop, Buenos Aires, 1981.

Kaplan de Drimer, A.: "Las cooperativas ante los peligros de "Desnaturalización" y "Desmutualización"», en Anuario de Estudios Cooperativos, Universidad de Deusto, Bilbao, 2000, pp. 167-176.

LEZCANO Y MAZÓN, A.M.: Constitución de Cuba (con los debates sobre su articulado y transitorias, en la Convención Constituyente), t. II, Ed. Cultural, La Habana, 1941.

LÓPEZ, C.: «¿En qué consiste la autonomía del Derecho Cooperativo?», en http://www.derechocomercial.edu.uy/ClaseCoopeAut01.htm, consultado en mayo de 2010.

Llobregat Hurtado, M. L.: Mutualidad y empresa cooperativa, Ed. José M. Bosch, Barcelona, 1990.

Montenegro De Siquot, O. J. y De Gregorio, E.: «El marco jurídico del cooperativismo y las entidades de economía social en la Argentina», en www.fundace.org.br/cooperativismo/arquivos_pesquisa/047-siquot.pdf, consultado en diciembre de 2009.

Monzón CAMPOS, J.L.: "Las cooperativas de trabajo asociado ante las reformas de los principios cooperativos», en www.dialnet.unirioja.es/servlet/fichero_ articulo?codigo=1148537\&orden, consultado en diciembre de 2009.

PASTOR SAMPERE, C.: «Empresa cooperativa y modelo constitucional: una aproximación», en Revista de Derecho de Sociedades, n. 17, Alicante, 2001, pp. 191-214.

Prieto Valdés, M.: «La reforma a la Constitución cubana de 1976», en Pérez Hernández, L. y Prieto Valdés, M. (compiladoras): Temas de Derecho Constitucional cubano, Ed. Félix Varela, La Habana, 2004, pp. 45-50.

- «Las funciones de la Constitución», Revista Jurídica, año 5, n. ${ }^{\circ}$ 9, enero-junio 2005, MINJUS, La Habana, pp. 38-46.

Rodríguez García, J.L.: «La perestroika en la economía soviética 1985-1991», en Revista Internacional Marx Ahora, n. ${ }^{\circ} 22$, La Habana, 2006, pp. 50-72.

Rodríguez Musa, O.: La cooperativa como figura jurídica. Perspectivas constitucionales en Cuba para su aprovechamiento en otros sectores de la economía nacional además del agropecuario, Ed. Dikinson SL., Madrid, 2012.

- «Socialismo, Cooperativismo y Derecho. Dialéctica necesaria para la actualización del modelo económico cubano», Boletín de la Asociación Internacional de Derecho Cooperativo, n. ${ }^{\circ} 46$, año 2012, Universidad de Deusto, España, pp. 93-102. 
Sanchez Calero, F.: Instituciones de Derecho Mercantil, vol. 1, Ed. Mac Graw Hill, Madrid, 2004.

SCHUJMAN, L.: «La línea ortodoxa cooperativa, el cooperativismo tradicional», en Congreso de Cooperativismo, Universidad de Deusto, Bilbao, 1988, pp. 163-182.

TORRES y TORRES LARA, C.: Naturaleza jurídica de la cooperativa, Lima, 1983, en http://www.teleley.com/librosdederecho/7tc.pdf, consultado en septiembre de 2010.

TRujllllo Diez, I. J.: «El valor jurídico de los principios cooperativos. A propósito de la Ley 27/1999, de 16 de julio, de cooperativas», (resumen) en http:// vlex.com/vid/cooperativos-proposito-cooperativas-324086, consultado en diciembre de 2009.

UnAl Del Burgo, D.: «La desnaturalización de las cooperativas. Estudio de los instrumentos financieros de carácter societario y del modelo de expansión "no-cooperativo" de Eroski S. Coop.», en Boletín de la Asociación Internacional de Derecho Cooperativo, n. ${ }^{\circ}$ 36, Facultad de Derecho, Universidad de Deusto, Bilbao, 2002, pp. 51-70.

UríA, R.: Derecho Mercantil, Marcial Pons, Madrid, 2000.

Vega Vega, J.: Cuba, su historia constitucional. Comentarios a la Constitución cubana reformada en 1992, Ed. Endymion, Madrid, 1998.

- Derecho Constitucional revolucionario en Cuba, Ed. Ciencias Sociales, La Habana, 1988.

Vicent ChuliA, F.: Compendio crítico de Derecho Mercantil, t. I, Ed. José M. Bosch, Barcelona, 1991.

YERA, L.M.: «La ley olvidada de la transición y el proyecto económico socialista en el siglo XX|», en Revista Temas, n. ${ }^{\circ}$ 50-51, abril-septiembre, La Habana, 2007, pp. 109-125.

\section{Otros documentos}

Acta de la sesión de debate 69, del 4 de junio de 1940, en LezCANo y MAzón, A.M.: Constitución de Cuba (con los debates sobre su articulado y transitorias, en la Convención Constituyente), t. II, Ed. Cultural, La Habana, 1941.

Acta contentiva de la discusión del Proyecto de Ley de Reforma Constitucional, Décimo Período Ordinario de Sesiones, Tercera Legislatura de la Asamblea Nacional del Poder Popular, días 10, 11 y 12 de julio de 1992.

Alianza CoOperativa Internacional: Conversatorio con la Alianza Cooperativa Internacional, en www.mincomercio.gov.co/econtent/documentos/Prensa/ doc, consultado en diciembre 2009.

- Declaración Sobre la Identidad Cooperativa, Manchester, 1995, en http:// www.elhogarobrero1905.org.ar, consultada en diciembre de 2009.

- Ley Marco para las Cooperativas de América Latina, San José, 2009, en www.aciamericas.coop, consultada en diciembre de 2009. 
- Los Principios Cooperativos para el siglo XXI (Documento de referencia acerca de la Declaración sobre la Identidad Cooperativa), publicado por El Hogar Obrero: Cooperativa de Consumo, Edificación y Crédito Ltda., en http://www.elhogarobrero1905.org.ar, consultado en diciembre de 2009.

Conferencias de Orientación Ciudadana. Los partidos políticos ante la Asamblea Constituyente de 1940, Ed. Club Atenas, La Habana, 1939.

Conferencia de actualización "El Sistema Empresarial estatal cubano», impartida por Carlos García Pérez (funcionario del Consejo de la Administración Provincia en Pinar del Río) en el Diplomado de Administración Pública para Cuadros del Partido, el Estado y el Gobierno en la Provincia de Pinar del Río, 2. ${ }^{a}$ edición, 13 de mayo de 2012.

Discurso pronunciado por el entonces Primer Vicepresidente de los Consejos de Estado y de Ministros, General de Ejército Raúl Castro Ruz, en el acto central con motivo del aniversario 54 del asalto a los cuarteles Moncada y Carlos Manuel de Céspedes, en la Plaza de la Revolución Mayor General Ignacio Agramonte Loynaz de la ciudad de Camagüey, el 26 de julio del 2007.

Discurso pronunciado ante la Asamblea Nacional del Poder Popular, en su Tercer Período Ordinario de Sesiones de la VII Legislatura, en el Palacio de Convenciones, el $1 .^{\circ}$ de agosto de 2009, por el Presidente de los Consejos de Estado y de Ministros, General de Ejército Raúl Castro Ruz, en www. cubadebate.cu/raul-castro-ruz/2009/08/01/raul-castro-discurso-asambleanacional-poder-popular, consultado en octubre de 2010.

Discurso pronunciado ante la Asamblea Nacional del Poder Popular, el domingo 20 de diciembre de 2009 del Presidentes de los Consejos de Estado y de Ministros, Raúl Castro Ruz, en www.cubadebate.cu/ opinion/2009/12/20/discurso-de-raul-castro-en-la-asamblea, consultado en octubre de 2010.

Intervención de Marino Murillo Jorge, Vicepresidente del Consejo de Ministros y Ministro de Economía y Planificación, en la clausura del X Congreso de la ANAP, efectuado en la Sala Universal de las FAR, el 16 de mayo de 2010, en www.cubadebate.cu/especiales/2010/05/17/actualizar-nuestro-modeloeconomico, consultado en octubre de 2010.

Pronunciamiento de la Central de Trabajadores de Cuba del 13 de septiembre 2010, en www.cubadebate.cu/noticias/2010/09/13/reducira-cuba-mediomillon-de-plazas-en-el-sector-estatal, consultado en octubre de 2010.

Lineamientos de la Política Económica y Social del Partido y la Revolución, aprobado por el VI Congreso del Partido Comunista de Cuba el 18 de abril de 2011, en www.cubadebate.cuwp-contentuploads201105folleto-lineamientos-vi-cong.pdf, consultados en junio de 2011. 